NBER WORKING PAPER SERIES

\title{
FAMILY SPILLOVERS OF LONG-TERM CARE INSURANCE
}

\author{
Norma B. Coe \\ Gopi Shah Goda \\ Courtney Harold Van Houtven \\ Working Paper 21483 \\ http://www.nber.org/papers/w21483
NATIONAL BUREAU OF ECONOMIC RESEARCH
1050 Massachusetts Avenue
Cambridge, MA 02138

August 2015

We would like to thank Jillian Boles for exceptional research assistance. This paper benefitted from discussions with Anirban Basu, Mark Duggan, Dan Fetter, Joanna Lahey, Kathleen McGarry, Meghan Skira, and Heidi Williams, and Reagan Baughman provided helpful comments at the fall 2014 APPAM annual meeting. This research was supported by an R-01 from the National Institute of Nursing Research, National Institutes of Health, entitled "Family Structure, Informal Care, and Long-term Care Insurance" (NIH 1R01NR13583; Van Houtven, PI). Our collaboration with R. Tamara Konetzka, Nina Sperber, Corrine Voils, and Ila Broyles on other aims of this grant has informed and enriched our approach in this particular paper. The views expressed herein are those of the authors and do not necessarily reflect the views of the National Bureau of Economic Research.

NBER working papers are circulated for discussion and comment purposes. They have not been peerreviewed or been subject to the review by the NBER Board of Directors that accompanies official NBER publications.

(C) 2015 by Norma B. Coe, Gopi Shah Goda, and Courtney Harold Van Houtven. All rights reserved. Short sections of text, not to exceed two paragraphs, may be quoted without explicit permission provided that full credit, including (C) notice, is given to the source. 
Family Spillovers of Long-Term Care Insurance

Norma B. Coe, Gopi Shah Goda, and Courtney Harold Van Houtven

NBER Working Paper No. 21483

August 2015

JEL No. H5,H75,I13,J12,J14,J22

\section{ABSTRACT}

We examine how long-term care insurance (LTCI) affects family outcomes expected to be sensitive to LTCI, including utilization of informal care and spillover effects on children. An instrumental variables approach allows us to address the endogeneity of LTCI coverage. LTCI coverage induces less informal caregiving, suggesting the presence of intra-family moral hazard. We also find that children are less likely to co-reside or live nearby parents with LTCI and more likely to work full-time, suggesting that significant economic gains from private LTCI could accrue to the younger generation.

Norma B. Coe

H-683 Health Sciences Building

Box 357660

University of Washington

1959 NE Pacific

Seattle, WA 98195

and NBER

nbcoe@uw.edu

Gopi Shah Goda

Stanford University

SIEPR

366 Galvez St.

Stanford, CA 94305

and NBER

gopi@stanford.edu
Courtney Harold Van Houtven

Department of Medicine

Division of General Intern

Duke University Medical Center

Durham, NC 27705, USA

courtney.vanhoutven@duke.edu 


\section{INTRODUCTION}

It is a puzzle why so few people purchase long-term care insurance (LTCI). Although long-term care (LTC) is one of the biggest financial risks facing the elderly today, very few-13\% of current 65 year olds-are insured against this risk. In all, \$49.3 billion was spent out-of-pocket on LTC in 2012 in the US (CMS 2014). Although factors such as Medicaid crowd-out and high administrative costs in a small market undoubtedly play a role, no single factor has been found to dominate (Brown and Finkelstein 2011; Brown, Goda and McGarry 2012).

Individual lack of private LTC insurance (LTCI) is a major policy concern for three reasons. First, recent efforts to expand LTCI coverage through public provision as part of the CLASS Act failed. Second, the lack of private LTCI leads to high public expenditures on LTC through Medicaid and out-of-pocket LTC expenses are associated with high poverty rates in old age. Third, demographic changes underscore the urgent need to find policy solutions, as the need for LTC will inevitably increase in the next few decades (Kaye 2012).

The high cost of care and the limited public and private LTCI among the elderly in the US means that most elderly disabled persons receive care exclusively from family members or friends. Nearly $87 \%$ of community-residing elderly needing assistance receive care exclusively from informal sources, and even among the most disabled elderly, two-thirds of them receive only informal care (Thompson 2004). However, this pattern of care may not be stable due to changing demographics. Smaller families, increased geographic dispersion within families, dual workers among working-age couples, increased divorce rates and delayed fertility all lead to increasing constraints on the traditional supply of informal care providers, namely spouses and adult children, among the elderly. Yet despite these trends, LTCI coverage remains modest. 
Researchers have spent great effort to understand why there is such low demand for LTCI, and have documented both supply-side and demand-side explanations (Brown and Finkelstein, 2011). One important category of demandside explanations is family interactions and intra-family moral hazard. That is, parents do not buy LTCI because they prefer children to care for them and do not want to enter a nursing home (Pauly 1990). Theory suggests that if the cost of accessing a nursing home were lower because of the purchase of insurance, children would change their behavior and be less likely to provide care. Another family-related theory for the low LTCI coverage rates is the presence of strategic bequest motives, which suggest that parents would not buy LTCI but instead use that wealth to invoke attention from children, via inter vivos transfers and bequests (Bernheim, Schleifer, and Summers 1985). Both theories predict a decline in informal care in response to holding LTCI. Thus, our first objective is to estimate the causal impact of LTCI on the expectations for future informal care, as well as to quantify how LTCI coverage impacts actual utilization of familyprovided informal care.

Several studies have documented demand for LTCI decreasing in the number of children (Mellor 2001), but to our knowledge, no previous work has investigated the effect of LTCI on informal caregiving in the US. ${ }^{1}$ In addition, while previous studies have examined the relationship between informal care and LTC use or costs, none have addressed the endogeneity of LTCI (Engers and Stern 2002, Van Houtven and Norton 2004, 2008, Charles and Sevak 2005). ${ }^{2}$

\footnotetext{
${ }^{1}$ Courbage and Roudaut (2010) simultaneously estimate informal care and formal home care use using cross-sectional data for France. They find that insurance for formal home care is associated with lower probability of receipt of informal care, but do not examine other family-related outcomes. More recently, Costa-Font and Courbage (2015) find that informal care expectations are endogenous to LTCI expectations.

${ }^{2}$ One exception is recent work by Konetzka, He, Guo and Nyman (2014), which tests for the presence of traditional moral hazard in the LTCI market by estimating the impact of LTCI on
} 
We overcome this limitation of the literature with the use of instrumental variables techniques and a previously tested instrumental variable to estimate the causal relationship between LTCI and informal care use, namely exogenous variation in LTCI ownership resulting from the implementation of state tax subsidies for LTCI. Using this empirical strategy, we find that LTCI reduces both the expectations for receiving informal care, mainly from relatives, and actual informal care utilization. Our findings are consistent with the presence of intrafamily moral hazard or strategic bequest motives being contributing factors to low LTCI coverage rates.

The presence of strategic bequest motives also predicts that parents will decrease financial transfers to their children who are no longer needed to provide informal care. Our second objective is to estimate the causal impact of LTCI on parent-child financial transfers to test this prediction. We find decreased inter vivos transfers, but no changes in expectations about the probability of leaving a bequest to children or the probability that a child is named in a will. This is consistent with previous findings that inter vivos transfers are more sensitive than actual bequests (McGarry 1997), and suggestive evidence of strategic bequest motives.

Beyond the relationship between LTCI and informal care, it is critical to understand how LTCI coverage may impact other family behaviors for several reasons. First, intra-family moral hazard predicts the potential informal caregivers are "freed" from their potential informal care responsibilities and now have the option to pursue other activities. Examining how LTCI impacts family behaviors tests the relevance of the intra-family moral hazard theory in this setting. Second, LTCI may impact family behaviors before the onset of a 
disability, and regardless of whether or not an LTC need develops. If that is the case, focusing only on LTC outcomes such as informal care may miss much of the effect of LTCI on the family. Our third objective, and a unique contribution of this paper, is that we consider the causal impact of private LTCI coverage on the behavior of the adult children - outside of the provision of informal care.

Our paper informs policymakers about the extent to which formal insurance may or may not crowd out informal care as well as the extent to which formal insurance frees up family resources to be used in other ways, regardless of disability onset. Utilizing the same empirical strategy to identify exogenous variation in LTCI coverage, we find that LTCI leads to a reduction in child coresidence and a shift from part-time to full-time employment by adult children. These results suggest the presence of intra-family moral hazard may be a factor in explaining the low LTCI coverage rates. Further, these findings suggest that LTCI ownership confers considerable economic gains to the next generation.

In Section II we introduce a conceptual framework, hypotheses, and describe the potential sources of endogeneity and our approach to address it. Section III presents the data, sample selection criteria, and measures. Section IV provides the methods and Section V presents the main results. Section VI concludes.

\section{CONCEPTUAL FRAMEWORK}

By changing the relative price of different types of care at the point of disability, long-term care insurance may influence expectations about long-term care utilization even prior to a disability occurring. Beyond thinking about adverse selection in the LTCI market (Finkelstein and McGarry 2006, Finkelstein, McGarry, and Sufi 2005), or traditional moral hazard (Konetzka et al. 2014), LTCI may also affect other types of family behavior if either intra-family moral hazard or strategic bequest motives are operating. In this section, we provide a 
framework for interpreting the effects of LTCI on the different types of outcomes we examine. We also describe how we are able to identify the effects of LTCI on these outcomes using exogenous variation in LTCI coverage.

Intra-family moral hazard. In contrast to traditional moral hazard, which focuses on the change in behavior of the insured individual, intra-family moral hazard argues that the behavior of other family members may also be impacted (Courbage and Roudaut 2010). Pauly (1990) posits that a large reason why LTCI demand is low is because parents prefer informal care from children. This preference, combined with the knowledge that the relative prices for formal versus informal care change with the purchase of LTCI, leads to less LTCI coverage than otherwise. Intra-family moral hazard predicts that increases in LTCI would reduce the expectations for and actual utilization of informal care.

These changes in expectations, if also experienced by potential caregivers, could lead to changes in economic behavior by potential caregivers. For instance, parents covered by LTCI could cause a positive labor supply response among children due to the potential reduced demand for informal care from children, or for demand for shorter term informal care commitments. It could also lead to a reduction in child co-residence or geographic proximity to parents because parents now have other sources of LTC available. Recent qualitative work finds evidence of such planning; parents expressed buying LTCI because they did not want to burden their children with having to provide informal care, and LTCI would leave the role of children to provide attention but not caregiving (Sperber et al, 2014). This finding is also consistent with those in Brown and colleagues (2012) who show that 87 percent of respondents wished to not create a financial burden for family members if they need LTC.

Strategic bequest motives. Another theory we test is the presence of strategic bequest motives, or evidence that transfers are used by parents to invoke attention from children (Bernheim, Schleifer, and Summers 1985). Strategic 
bequest motives could operate both by changing the expectations of leaving bequests or naming children on parents' wills, or also through inter vivos transfers from parents to children while both are living.

The expected effect of LTCI on whether a person expects to leave a bequest may be negative for two reasons. First, LTCI premiums are a known expense which would lower bequeathable wealth even if LTC is not needed. Some evidence suggests that bequest motives are negatively correlated with purchase of LTCI (Lockwood In press). Second, if parents use a promise of a bequest to elicit informal care from their children (Zweifel and Struewe 1998) and LTCI decreases the demand for informal care, then the desire to leave a bequest is also lower. Similarly, net transfers from parents to children also will fall. However, LTCI is also sometimes seen as a way to protect bequests and evidence suggests demand for LTCI is positively correlated with bequest motives (Brown, Goda, and McGarry 2012). In this case, LTCI may increase the probability of leaving bequests, and thereby expectations surrounding leaving a bequest or naming a child on a will. Overall, with these countervailing factors, it is unclear what the net impact of LTCI on bequests or transfers will be.

Addressing bias from unobserved differences. To test these hypotheses, we need empirical methods that account for potential selection into LTCI coverage. There is great concern that people who buy LTCI are different than those who do not (Finkelstein and McGarry 2006, Finkelstein, McGarry, and Sufi 2005), and that we cannot measure these differences in the data. Instrumental variables estimation can reduce bias from selecting LTCI on non-random factors, such as higher likelihood of using long-term care in the future due to unobserved health problems (adverse selection) or other unobservables, such as the inability to control well for risk aversion. The literature has posed a variety of potential instruments that influence LTCI decisions. The key considerations in the identification of a causal effect are whether the potential instruments strongly 
predict LTCI holding and are otherwise uncorrelated with the outcome measures. Li (2011) proposes two variables: whether an individual has purchased a life insurance policy, and the price one faces for a LTCI policy. While these two variables predict LTCI purchase, they are likely to also influence informal care use separately, making them inappropriate to use in this context.

Courtemanche and He (2009) examine a federal tax subsidy for LTCI premiums implemented as part of HIPAA in 1996. The tax subsidy was available to all tax filers who itemized their deductions and whose medical expenses (including the LTCI premium) exceeded $7.5 \%$ of their adjusted gross income. While the average amount of the subsidy was substantial, it was only applicable to the $14 \%$ of the sample who itemized their medical expenses. The authors find that the subsidy strongly influences LTCI purchase and that federal tax policy is unlikely to separately influence LTC use. However, the federal tax subsidies were implemented at the same time for the whole population, making identification difficult. Additionally, their approach implicitly assumes that taxpayer itemizing and incurring catastrophic medical expenses is both persistent and exogenous to LTCI purchase, which seems unlikely if current medical expenses are correlated with future LTC expenses.

Goda (2011) improves upon previous approaches by using variation in state tax policy for LTCI policies. She uses both date of adoption of the tax break and the generosity of the tax break to predict LTCI coverage. These instruments vary considerably over time and state; while only three states had tax incentives for LTCI in 1996, by 2010, 24 states and the District of Columbia had adopted a subsidy. Of the states that offered subsidies, 16 allowed taxpayers to deduct all or a portion of their premiums from their income for state tax purposes, and the other 9 offered credits for a certain percentage of premiums. The average value of the tax subsidies was $4.6 \%$ of premiums, with significant variation by state (range $0 \%$ to $20 \%$ ). Goda (2011) shows that these are empirically important in whether 
someone is covered by LTCI. By measuring the response in LTCI coverage within states as tax subsidies are implemented, she finds that the average state tax subsidy leads to a substantial 28 percent increase in LTCI coverage rates.

Using this instrumental variables strategy requires the assumption that state tax subsidies only impact our outcome variables along the extensive margin of insurance coverage, conditional on controls. This assumption would be violated if there were legislative endogeneity, i.e. LTCI tax incentives were enacted at the same time as changes in the Medicaid program (which provides implicit LTCI coverage) or rating regulations. Goda (2011) examined any changes in Medicaid eligibility or age ratios (which are related to rating regulations), to ensure that they were not occurring at the same time the changes in LTCI tax policy were occurring. This study found that the implementation of tax subsidies was unrelated to these other factors.

The instrument would be invalid if the tax subsidies also influenced the outcomes we examine through the intensive margin of coverage, by moving some people to purchase more generous policies. There is some evidence that tax subsidies were associated with the purchase of more generous policies (Goda 2011); however, this analysis will allow us to estimate the magnitude of the impact of LTCI on informal care utilization and other outcomes that would be necessary for the extensive margin to be the only channel through which tax subsidies affected the outcomes of interest.

The assumptions necessary for an instrumental variables approach would also be violated if the outcomes we analyze change for those who do not purchase LTCI due to peer effects or spillovers. Given the large percentage of individuals who remain uninsured for LTC following the implementation of subsidies, we believe these are quantitatively small.

\section{DATA}


We use data from eight waves of the HRS (1996-2010), a publicly available, bi-annual survey of the near elderly in the U.S. ${ }^{3}$ The HRS is the only nationally representative data set with extensive information on family characteristics, long-term care insurance, informal care expectations and use. Respondents were ages 50 and older when they entered the sample initially, thus, during the sample period they are old enough to have formed expectations and decisions about LTC planning and LTCI purchase. Many respondents are also observed long enough to have used informal care, formal LTC, or both. We use the Cross-Wave Geographic Information (State) ${ }^{4}$ file in order to match respondents to their state of residence and use the state-level variation in LTCI tax incentives. Finally, we have collected individual state income tax return forms from 1996-2010 which contain details of tax incentive programs for private LTCI. The variables coded include whether a tax subsidy is available, whether the subsidy is in the form of a credit or a deduction, the fraction of premiums eligible or monetary caps on the value of the subsidy, income limits, and whether the state subsidy is available in addition to the federal subsidy (Goda 2011).

Sample. Our identification strategy relies on the state tax subsidies for LTCI affecting holding of private LTCI directly. As such, we limit the sample to individuals who report filing taxes since the tax subsidy would only lower the effective out-of-pocket price of a policy among those who could actually claim the subsidy. While the state tax subsidy could, in theory, impact the LTCI purchase decisions of all tax filers, preliminary analysis found that the instrument is strongest for tax filing individuals with at least median income. This intuitively makes sense, since the subsidy is larger for individuals with larger tax bills, and

\footnotetext{
${ }^{3}$ We use the 1996-2010 waves because earlier waves have lower quality information on the LTCI question (Finkelstein and McGarry, 2006), which is key to our analysis, and state geographical codes are not yet available for the 2012 wave.

${ }^{4}$ We obtained these data by applying for access to the HRS Restricted Data.
} 
Medicaid could conceivably crowd-out LTCI demand for individuals in the lower portion of the income distribution (Brown and Finkelstein 2008). Therefore, caution is warranted in generalizing our results to non-tax-filers or those with below-median income.

There may be a concern that our analysis includes individuals who will self-insure no matter what LTCI subsidies are in place, and hence the instruments do not invoke these persons to purchase or hold LTCI. Brown and Finkelstein (2008) suggest that persons with wealth over \$3 million are the most likely to self-insure. In our data set, eliminating those with this level of wealth would eliminate less than 1 percent of the sample. Therefore, because such a small proportion of the sample is unlikely to introduce bias, we do not remove them; if bias is introduced, it would lead to an underestimation of the impacts of LTCI on our outcomes of interest.

Measures. We expand the outcome measures beyond LTC utilization to include expectations, informal care use, and family behavior.

\section{$\underline{\text { Expectations }}$}

Expectations of Future Informal Care. Informal care expectations are elicited: "Suppose in the future, you needed help with basic personal care activities like eating or dressing. Do you have relatives or friends [besides your spouse] who would be willing and able to help you over a long period of time?” For affirmative responses, follow up questions elicit the relationship of multiple potential care providers. We examine informal care expectations from any source, and by the type of provider (child, relative, or other).

Bequest Expectations. The HRS asks respondents to rank on a scale of 0 to 100: "What are the chances that you (and your [husband/wife/partner]) will leave any inheritance?” We dichotomize the answer to high chance (over 50 percent chance) and low chance, due to the prevalence of focal answers (Coe and Webb 2009). 
Informal care utilization.

Informal Helper. To define informal care receipt in the HRS one must use several questions, first examining whether the person gets help with specific IADLs and ADLs and then assessing if it was unpaid assistance by looking at relationship codes from the helper file to determine whether the care was from a child, a friend, a relative, or another unpaid person. Due to the longitudinal nature of the HRS, we are able to create indicators of help from an informal caregiver one, two, and three waves (i.e., up to six years) from when we observe the respondent being covered by LTCI.

Family behavior.

Child Co-Residence and Proximity to Parents. We construct a dependent variable indicating whether at least one child lives with the parent(s) and a separate variable indicating whether at least one child lives within 10 miles of the parent(s).

Child's current work behavior. We also construct dependent variables indicating whether at least one child works full-time and at least one works parttime. We follow the RAND definitions, where working full-time is $35+$ hours per week, 36+ weeks per year and working part-term is less than that.

Child financial relationship to parents. Finally, we also examine the financial relationship between children and parents. We examine whether the respondent gave financial help to at least one child, at least one child gave financial transfers to the respondent, and whether the respondent has a will or trust and names the child as a beneficiary.

\section{Explanatory variables.}

LTCI. Respondents in 1996 and later waves answer the following question: "Not including government programs, do you now have any long term care insurance which specifically covers nursing home care for a year or more or 
any part of personal or medical care in your home?” Individuals respond yes or no. LTCI Ownership is defined as having LTCI in time $t$.

The models also include binary controls for marital status, sex, number of children, retirement status, education, income, race, ethnicity, health status (fair or poor self-reported health and the presence of any limitations in the activities of daily living (ADLs)), and age fixed effects.

\section{METHODS}

The literature has focused thus far on regressions such as the following to test the positive correlation prediction that arises from the presence of adverse or dynamic selection (Finkelstein and McGarry 2006, Finkelstein, McGarry, and Sufi 2005)

$$
Y_{i t}=\alpha_{0}+\alpha_{1} L T C I_{i t}+\alpha_{2} \mathrm{X}_{\mathrm{it}}+\varepsilon_{i t}
$$

where $Y_{i t}$ is an outcome measure for individual $i$ in time $t . L T C I_{i t}$ is an indicator for whether an individual has private LTCI coverage, and $X_{i}$ is a vector of additional controls for individual-level characteristics. However, when examining the effect of LTCI on utilization, $\alpha_{1}$ is likely biased upwards if selection is not accounted for, i.e. if individuals who purchase LTCI have a higher likelihood of using LTC. In order to address this problem and measure causal effects, we propose estimating this relationship using instrumental variables techniques. We follow Goda (2011), and use variation in state tax policy for LTCI policies as an instrument to predict LTCI coverage. These instruments vary over the study period as adoption ramped up, and by state. Goda (2011) shows that these instruments are empirically strong in predicting whether someone holds LTCI.

Traditional two-stage least squares methods are inappropriate in this setting, where the endogenous variable and the dependent variables are binary, especially given the rarity of some of the outcome variables. Therefore we use 
nonlinear models and two stage residual inclusion (2SRI) methods (Terza, Basu, and Rathouz 2008). This approach includes the potentially endogenous regressor and the residual from the first-stage regression as an additional regressor in the second stage.

Our first stage equation is the following probit equation:

$$
L T C I_{i s t}=\Phi\left(\beta_{0}+\beta_{1} Z_{s t}+\beta_{2} X_{i t}+S_{s}+\lambda_{t}+u_{i s t}\right)
$$

Here, $L T C I_{\text {ist }}$ represents whether individual $i$ in time $t$ and state $s$ are covered by LTCI. $Z_{\text {st }}$ represents whether a tax subsidy is available in state $s$ in time $t . \mathrm{X}_{\mathrm{it}}$ represents the vector of individual time-varying controls, and $s_{s}$ and $\lambda_{t}$ represent state and year fixed effects respectively. We use the estimated coefficients from the first stage to generate residuals, $\hat{u}_{i s t}$. As indicated in Basu and Coe (2015), we calculate Anscombe residuals in the first stage to minimize bias. These residuals are then used in the second stage equation below

$$
Y_{i s t}=\Phi\left(\alpha_{0}+\alpha_{1} L T C I_{i s t}+\alpha_{2} \hat{u}_{i s t}+\alpha_{3} \mathrm{X}_{\mathrm{it}}+s_{s}+\lambda_{t}+\varepsilon_{\text {ist }}\right)
$$

where the variables are the same as described above. We use this model for estimating the causal effect of LTCI on our outcomes of interest: expectations about informal care and bequests, informal care use, and family behavior. Because one must be relatively healthy in order to purchase LTCI, the effect on informal care receipt might not be contemporaneous. Thus we also examine informal care receipt reported in waves $t+1, t+2$, and $t+3$, representing approximately the next two, four, and six years after we observe LTCI ownership. All models include year and state fixed-effects. The year fixed-effects account for time trends in the data while the state fixed-effects account for non-timevarying differences across states. The inclusion of state fixed-effects means we are identifying the effect of LTCI holding on our outcomes based on within-state differences in the state tax policy over time. 
We compute marginal effects from our 2SRI probit results using the recycled predictions approach, to account for the fact that the treatment variable is binary. The recycled prediction approach involves computing the marginal effects for each observation and then calculating the sample average of these marginal effects. For small samples, this method is preferred over calculating the marginal effect at the sample mean (Greene, 1997). In all models, we use population weights and cluster standard errors at the state level. In addition, we also perform a bootstrap procedure on standard errors for the second stage with 1000 iterations.

\section{RESULTS}

\section{Summary Statistics.}

Table 1 displays the characteristics of the sample. The sample inclusion criteria of being median income or higher and a tax filer is reflected in the 15.7 percent of respondents who are covered by private LTCI. Additionally, the sample has higher education levels and income than average Americans of a similar age, with two-thirds of respondents having at least some college completed. Predominantly married, white and female, 50 percent of the respondents had 3 or more children and almost half (46\%) were retired. Around $10 \%$ had at least one limitation in activities of daily living. Around one-third of the respondents were sampled in a year and state in which there was a tax subsidy or credit for long-term care insurance.

The outcomes are summarized in Table 2. Sixty percent of respondents reported having a high chance (e.g. >50\%) of receiving informal care overall, from caregivers other than a spouse. Most expected the informal care to come from a child rather than another source. One wave into the future, time $t+1$, informal care utilization was low: 9\% had informal care, reflecting the relative healthiness of the sample. Looking forward between the current wave, $t$, to $t+2$, 
which signifies between a 4 to 5 years period depending on the interview dates, around $16 \%$ of respondents received informal care. From wave $t$ to wave $t+3$, around $25 \%$ of respondents reported receiving informal care. Around $24 \%$ of respondents had a child living with them, half had a child living nearby, and almost all (92\%) had at least one child working full time. It was much more common for parents to give financial transfers of at least $\$ 500$ to adult children than for children to give financial transfers to a parent, at $57 \%$ and $3 \%$ respectively. Around half of respondents named a child on their will.

\section{$\underline{\text { Regression Results. }}$}

Table 3 presents our main results of the impact of LTCI coverage on expectations regarding informal care use: informal care from any source (column (1)), informal care from a child (2), informal care from a relative other than a spouse or a child (3) and informal care from other individuals (4). The last column (5) shows the impact of LTCI on expectations of leaving a bequest. The table presents the marginal effects, bootstrapped standard errors, and $p$-values from two-stage residual inclusion methods (see the Appendix for the reduced form probit results). For ease of interpretation of the magnitude of the marginal effects, all tables include the mean of the dependent variable. Since the sample varies slightly based on the outcome measure used due to individual nonresponse, the each column also includes the first stage marginal effect of the tax subsidy indicator and F-statistic to assess the strength of the first stage (full firststage results are available upon request).

Intra-family moral hazard and the strategic bequest motive predict that LTCI would decrease the expectations for receiving informal care in the future. In line with these hypotheses, we find a statistically significant reduction in the expectation of receiving informal care in Column (2). This reduction appears to be due to reductions in expectations of receiving informal care from relatives 
(Column (4)). In fact, the estimated impact on expectations on the extended family is quite large, with a 15.6 percentage point decrease in the percent of the population that expects care from an extended family member, on a mean of 16.5 percent. This is suggestive of a 95 percent crowd-out rate from this source of informal care. We do not find evidence that the expected probability of leaving a bequest changes, leaving some question as to whether a strategic bequest motive is at play.

We next examine realized informal care utilization patterns in Table 4, reporting marginal effects, bootstrapped standard errors, and p-values as discussed earlier. We find evidence of intra-family moral hazard; LTCI lowers the use of an informal helper. The results in Table 4, Column (1) imply that LTCI induces an 8.9 percentage point reduction in use of an informal helper, and this effect also persists two and three waves ahead, about 4 and 6 years ahead. The magnitude of these effects are large compared to the mean, suggesting near 100 percent crowd-out rates. Note that while the results are consistent, the strength of our first stage is lower when looking additional years ahead as shown by the decreasing F-statistic. Therefore, we have limited power to detect differences in outcomes in waves $t+3$ and beyond.

Finally, we examine if LTCI coverage influences behavior of the children, the potential future informal caregivers, in Table 5, which follows a format similar to previous tables. We find a large reduction in child co-residence: LTCI leads to a 24.4 percentage point decrease in the likelihood of living with a child. However, we do not find evidence that the probability that any child lives within 10 miles changes. In addition to being less likely to live with their parents, children whose parents have LTCI also appear to increase their work effort. LTCI coverage among parents increases the probability of any child working full-time by 7.3 percentage points and decreases the likelihood of part-time work by 15.6 percentage points. 
To test the strategic bequest motive, we then examine whether intergenerational financial transfers respond to LTCI coverage. Despite this change in labor supply and living arrangements, LTCI does not substantially impact whether children help their parent financially. This finding could be due to the extremely low incidence of financial transfers to parents; around 3\% of respondents report receiving any financial transfer from any children (Table 2). By contrast, inter vivos transfers to the younger generation are sensitive to LTCI coverage. We find that LTCI decreases the probability of reporting providing a financial transfer of at least $\$ 500$ to a child by 30 percentage points (Table 5, Column (5)). However, we find no evidence that LTCI causes parents to change the likelihood of naming their children in their will (Table 5, Column (7)). This finding is consistent with McGarry (1997), who found inter vivos transfers much more responsive to changes in income than bequests.

\section{CONCLUSION}

While some recent policy efforts to increase long-term care insurance ownership have resulted in higher rates of LTCI ownership, the reasons why a large percentage of the elderly population remain exposed to LTC expenditure risk remain in doubt. In this paper, we estimate the causal effects LTCI has on informal care, including both expectations and utilization, and other family behaviors such as labor supply decisions and financial relationships between parents and adult children in order to test the theoretical predictions of intrafamily moral hazard and strategic bequest motives.

Our findings support the presence of intra-family moral hazard, including lowered expectations of informal care from extended family members, reductions in informal care received, and changes in the behavior by adult children that is consistent with a smaller role in caring for parents now and in the future (less co- 
residence and higher labor force attachment). We also find some evidence consistent with the presence of strategic bequest motives in LTCI coverage leads to fewer inter vivos financial transfers to children. Although we do not see any changes in the probability of leaving a bequest or naming a child on a will as a result of having LTCI, these results are less surprising given the lack of specificity in the question asking about bequests in the HRS and the general norm of dividing assets in wills in non-strategic ways (Norton and Taylor 2005, Norton and Van Houtven 2006).

An important caveat to our findings is their generalizability. First, our sample is limited to individuals with above median wealth and who file a tax return, and may not apply to the population as a whole. Making this sample restriction allows us to use an instrumental variables approach and leads us to focus on those most likely to purchase private LTCI. Second, our identification comes from focusing on individuals who are induced to hold LTCI due to a slight reduction in price through the tax code. Thus, one needs to consider whether these individuals and their children are different from other people that policy makers want to target to buy LTCI using different tools.

This study uses the best national source of LTCI and LTC data available, and carefully considers the endogeneity of purchase decisions in answering how LTCI affects informal care use and family behavior. Our paper is the first that empirically tests for intra-family moral hazard while addressing the endogenous nature of LTCI and LTC use. Furthermore, understanding how LTCI affects family behavior is a unique contribution and important to consider in the policy debate, as the economic gains accruing to the younger generation may be substantial. Our paper informs policymakers about the extent to which formal insurance may or may not crowd out informal insurance mechanisms and the extent to which insurance frees up family resources, regardless of disability onset. 


\section{References}

Basu, A , and NB Coe. 2015. 2SLS vs 2SRI: Appropriate methods for rare outcomes and/or rare exposures. University of Washington.

Bernheim, B.D., A. Schleifer, and LH Summers. 1985. "The strategic bequest motive." Journal of Political Economy no. 93:1045-1076.

Brown, J. R., G. S. Goda, and K. McGarry. 2012. "Long-term care insurance demand limited by beliefs about needs, concerns about insurers, and care available from family." Health Aff (Millwood) no. 31 (6):1294-302. doi: 10.1377/hlthaff.2011.1307.

Brown, JR, and AN Finkelstein. 2008. "The Interaction of Public and Private Insurance: Medicaid and the Long-Term Care Insurance Market." no. 98 (3):1083-1102.

Charles, K. K., and P. Sevak. 2005. "Can family caregiving substitute for nursing home care?" Journal of Health Economics no. 24 (6):1174-90.

CMS. 2014. National Health Expenditure Tables. edited by Centers for Medicare and Medicaid Services: CMS.

Coe, NB, and A Webb. 2009. Actual and Anticipated Inheritance Receipts. In Center for Retirement Research. Boston College.

Courbage, C, and N Roudaut. 2010. Informal care, insurance, and intra-family moral hazard: evidence from France. In Working Paper Seriew of the Geneva Foundation. Geneva, Switzerland.

Courtemanche, C, and D He. 2009. "Tax Incentives and the Decision to Purchase Long-Term Care Insurance." Journal of Public Economics no. 93 (12):296-310.

Engers, M., and Steven Stern. 2002. "Long-term care and family bargaining." International Economic Review no. 43 (1):1-41. 
Finkelstein, A, K McGarry, and A Sufi. 2005. "Dynamic Inefficiencies in Insurance Markets: Evidence from Long-Term Care Insurance.” " American Economic Review no. 95 (2):224-228.

Finkelstein, AN, and K McGarry. 2006. "Multiple dimensions of private information: evidence from the long-term care insurance market." American Economic Review no. 96 (4):938-958.

Goda, GS. 2011. "The Impact Of State Tax Subsidies For Private Long-Term Care Insurance On Coverage And Medicaid Expenditures." Journal of Public Economics no. 95 (7-8):744-757.

Kaye, SH. 2012. "Meeting Demand While Saving Money: How States Can ReBalance and Reduce Medicaid Long-Term Services Spending." Health Affairs no. 31 (6).

Konetzka, R. T., D He, J. Guo, and J. A. Nyman. 2014. Moral Hazard and LongTerm Care Insurance. In Working Paper. University of Chicago.

Li, Yong, and G. Jensen. 2011. "The Impact of Private Long-Term Care Insurance on the Use of Long-Term Care." Inquiry no. 48 (1):34-50.

Lockwood, L. In press. "Incidental Bequests: Bequest Motives and the Choice to Self-Insure Late-Life Risks." American Economic Review.

McGarry, K. 1997. Inter vivos Transfers and Intended Bequests. In NBER Working Paper

Mellor, J. M. 2001. "Long-term care and nursing home coverage: are adult children substitutes for insurance policies?" J Health Econ no. 20 (4):52747.

Norton, EC, and D Taylor. 2005. "Equal Division of Estates and the Exchange Motive." Journal of Aging \& Social Policy no. 17 (1):63-82.

Norton, EC, and CH Van Houtven. 2006. "Inter-vivos transfers and exchange." Southern Economic Journal no. 73 (1):157-172. 
Pauly, Mark V. 1990. "The Rational Nonpurchase of Long-Term Care Insurance." Journal of Economic Perspectives no. 6 (3):3-21.

Terza, J. V., A. Basu, and P. J. Rathouz. 2008. "Two-stage residual inclusion estimation: addressing endogeneity in health econometric modeling." $J$ Health Econ no. 27 (3):531-43.

Thompson, L. 2004. Long-term care: Support for family caregivers In Issue Brief:Long-Term Care Financing Project. Georgetown Univesrity.

Van Houtven, CH, and EC Norton. 2004. "Informal Care and Elderly Health Care Use." Journal of Health Economics no. 23 (6):1159-1180.

Van Houtven, CH, and EC Norton. 2008. "Informal Care and Medicare Expenditures:Testing for Heterogeneous Treatment Effects." Journal of Health Economics no. 27:134-156.

Zweifel, P., and W Struewe. 1998. "Long-term care insurance in a two-generation model." Journal of Risk and Insurance no. 65:13-32. 
Table 1: Summary Statistics: Controls

\begin{tabular}{lcccc}
\hline \hline & mean & sd & min & max \\
\hline LTCI Coverage & 0.157 & 0.364 & 0 & 1 \\
Divorced & 0.114 & 0.318 & 0 & 1 \\
Widowed & 0.165 & 0.371 & 0 & 1 \\
Unmarried & 0.0618 & 0.241 & 0 & 1 \\
Female & 0.557 & 0.497 & 0 & 1 \\
1 Child & 0.102 & 0.302 & 0 & 1 \\
2 Children & 0.307 & 0.461 & 0 & 1 \\
3+ Children & 0.505 & 0.500 & 0 & 1 \\
No. of Children Missing & 0.0132 & 0.114 & 0 & 1 \\
Retired & 0.466 & 0.499 & 0 & 1 \\
High School & 0.345 & 0.476 & 0 & 1 \\
Some College & 0.261 & 0.439 & 0 & 1 \\
College Plus & 0.303 & 0.459 & 0 & 1 \\
\$30K $<$ Income $\leq \$ 100 K$ & 0.361 & 0.480 & 0 & 1 \\
Income $>100 K$ & 0.639 & 0.480 & 0 & 1 \\
African American & 0.0649 & 0.246 & 0 & 1 \\
Other Race & 0.0316 & 0.175 & 0 & 1 \\
Fair/Poor Health Status & 0.166 & 0.372 & 0 & 1 \\
1+ ADLs & 0.0954 & 0.294 & 0 & 1 \\
Tax Subsidy & 0.335 & 0.472 & 0 & 1 \\
\hline Observations & 46639 & & & \\
\hline \hline Source: & & &
\end{tabular}

Source: HRS Waves 3-10 (1996-2010) 
Table 2: Summary Statistics: Outcomes

\begin{tabular}{|c|c|c|c|c|}
\hline & mean & $\mathrm{sd}$ & $\min$ & $\max$ \\
\hline \multicolumn{5}{|c|}{ Expectation Outcomes } \\
\hline Inf Care & 0.604 & 0.489 & 0 & 1 \\
\hline Inf Care-Kid & 0.432 & 0.495 & 0 & 1 \\
\hline Inf Care-Relative & 0.165 & 0.371 & 0 & 1 \\
\hline Inf Care-Other & 0.119 & 0.324 & 0 & 1 \\
\hline High $\operatorname{Pr}(\mathrm{Beq})$ & 0.830 & 0.375 & 0 & 1 \\
\hline \multicolumn{5}{|c|}{ Informal Care Utilization Outcomes } \\
\hline Informal Helper (Wave $t+1$ ) & 0.091 & 0.288 & 0 & 1 \\
\hline Informal Helper (Wave $t+2$ ) & 0.154 & 0.371 & 0 & 1 \\
\hline Informal Helper (Wave $t+3$ ) & 0.210 & 0.435 & 0 & 1 \\
\hline \multicolumn{5}{|c|}{ Child Outcomes } \\
\hline Child Co-Res & 0.245 & 0.429 & 0 & 1 \\
\hline Child $10 \mathrm{mi}$. & 0.513 & 0.500 & 0 & 1 \\
\hline Child FT & 0.919 & 0.273 & 0 & 1 \\
\hline Child PT & 0.242 & 0.428 & 0 & 1 \\
\hline R Helps Child & 0.569 & 0.495 & 0 & 1 \\
\hline Child Helps R & 0.031 & 0.173 & 0 & 1 \\
\hline Will Names Child & 0.592 & 0.492 & 0 & 1 \\
\hline Observations & 46639 & & & \\
\hline
\end{tabular}


Table 3: 2SRI Estimates of Effects of LTCI on Expectations

\begin{tabular}{|c|c|c|c|c|c|}
\hline & $\begin{array}{c}(1) \\
\text { Inf Care }\end{array}$ & $\begin{array}{c}(2) \\
\text { Inf Care-Kid }\end{array}$ & $\begin{array}{c}(3) \\
\text { Inf Care-Relative }\end{array}$ & $\begin{array}{c}(4) \\
\text { Inf Care-Other }\end{array}$ & $\begin{array}{c}(5) \\
\text { High } \operatorname{Pr}(\mathrm{Beq})\end{array}$ \\
\hline $\begin{array}{l}\text { Marginal Effect } \\
\text { Bootstrap S.E. } \\
\text { p-value }\end{array}$ & $\begin{array}{c}-0.202^{* *} \\
(0.096) \\
0.042\end{array}$ & $\begin{array}{c}-0.083 \\
(0.098) \\
0.403\end{array}$ & $\begin{array}{c}-0.157^{* * *} \\
(0.041) \\
0.000\end{array}$ & $\begin{array}{c}-0.032 \\
(0.043) \\
0.462\end{array}$ & $\begin{array}{c}-0.003 \\
(0.069) \\
0.967\end{array}$ \\
\hline Mean of DV & 0.603 & 0.432 & 0.165 & 0.119 & 0.830 \\
\hline $\begin{array}{l}\text { FS Marginal Effect } \\
\text { FS F-Statistic } \\
\text { Pseudo } \mathrm{R}^{2} \\
\text { Clusters } \\
\text { Observations }\end{array}$ & $\begin{array}{c}0.039 \\
13.688 \\
.0629 \\
48 \\
46,612\end{array}$ & $\begin{array}{c}0.039 \\
14.204 \\
.106 \\
49 \\
46,625\end{array}$ & $\begin{array}{c}0.039 \\
14.173 \\
.0911 \\
47 \\
46,589\end{array}$ & $\begin{array}{c}0.039 \\
13.974 \\
.0464 \\
48 \\
46,601\end{array}$ & $\begin{array}{c}0.039 \\
14.204 \\
.0927 \\
49 \\
46,625\end{array}$ \\
\hline
\end{tabular}

Source: HRS Waves 3-10 (1996-2010)

Notes: Dependent variable is as indicated in column heading. Sample includes individuals age 50 and above with above median income who report filing taxes. Long-term care insurance instrumented with indicator for state tax subsidy. All specifications include binary controls for marital status, sex, number of children, retirement status, education, income, race, ethnicity, fair/poor health status, ADLs, age, year, and state fixed effects and are estimated using population weights. Standard errors clustered at the state level. * Significantly different at the $10 \%$ level; ${ }^{* *}$ at the $5 \%$ level; ${ }^{* * *}$ at the $1 \%$ level. 
Table 4: 2SRI Estimates of Effects of LTCI on Informal Care Utilization

\begin{tabular}{lccc}
\hline \hline & $(1)$ & $(2)$ & $(3)$ \\
& Wave $t$ to $t+1$ & Wave $t$ to $t+2$ & Wave $t$ to $t+3$ \\
\hline Marginal Effect & $-0.089^{* * *}$ & $-0.096^{* *}$ & $-0.127^{*}$ \\
Bootstrap S.E. & $(0.031)$ & $(0.047)$ & $(0.063)$ \\
p-value & 0.007 & 0.045 & 0.051 \\
& & & \\
Mean of DV & 0.091 & 0.154 & 0.210 \\
& & & \\
FS Marginal Effect & 0.039 & 0.038 & 0.034 \\
FS F-Statistic & 13.681 & 10.677 & 7.601 \\
Pseudo R & .272 & .279 & .279 \\
Clusters & 46 & 48 & 49 \\
Observations & 46,592 & 39,420 & 31,891 \\
\hline \hline
\end{tabular}

Source: HRS Waves 3-10 (1996-2010)

Notes: Dependent variable is as indicated in column heading. Sample includes individuals age 50 and above with above median income who report filing taxes. Long-term care insurance instrumented with indicator for state tax subsidy. All specifications include binary controls for marital status, sex, number of children, retirement status, education, income, race, ethnicity, fair/poor health status, ADLs, age, year, and state fixed effects and are estimated using population weights. Standard errors clustered at the state level. * Significantly different at the $10 \%$ level; ${ }^{* *}$ at the $5 \%$ level; ${ }^{* * *}$ at the $1 \%$ level. 
Table 5: 2SRI Estimates of Effects of LTCI on Children Behavior

\begin{tabular}{|c|c|c|c|c|c|c|c|}
\hline & $\begin{array}{c}(1) \\
\text { Child Co-Res }\end{array}$ & $\begin{array}{c}(2) \\
\text { Child } 10 \mathrm{mi} .\end{array}$ & $\begin{array}{c}(3) \\
\text { Child FT }\end{array}$ & $\begin{array}{c}(4) \\
\text { Child PT }\end{array}$ & $\begin{array}{c}(5) \\
\text { R Helps Child }\end{array}$ & $\begin{array}{c}(6) \\
\text { Child Helps R }\end{array}$ & $\begin{array}{c}(7) \\
\text { Will Names Child }\end{array}$ \\
\hline Marginal Effect & $-0.244^{* * *}$ & 0.129 & $0.073^{* *}$ & $-0.156^{* *}$ & $-0.300 * * *$ & 0.002 & -0.052 \\
\hline Bootstrap S.E. & $(0.051)$ & $(0.133)$ & $(0.034)$ & $(0.074)$ & $(0.098)$ & $(0.038)$ & $(0.123)$ \\
\hline p-value & 0.000 & 0.339 & 0.039 & 0.040 & 0.003 & 0.951 & 0.677 \\
\hline Mean of DV & 0.245 & 0.513 & 0.919 & 0.242 & 0.569 & 0.031 & 0.592 \\
\hline FS Marginal Effect & 0.041 & 0.040 & 0.040 & 0.041 & 0.042 & 0.042 & 0.041 \\
\hline FS F-Statistic & 12.543 & 11.717 & 12.624 & 13.046 & 13.383 & 13.074 & 12.658 \\
\hline Pseudo $\mathrm{R}^{2}$ & .116 & .078 & .189 & .038 & .0996 & .094 & .146 \\
\hline Clusters & 48 & 47 & 45 & 48 & 49 & 42 & 49 \\
\hline Observations & 43,124 & 42,348 & 42,397 & 42,452 & 43,079 & 42,590 & 42,552 \\
\hline
\end{tabular}

Source: HRS Waves 3-10 (1996-2010)

Notes: Dependent variable is as indicated in column heading. Sample includes individuals age 50 and above with above median income who report filing taxes. Long-term care insurance instrumented with indicator for state tax subsidy. All specifications include binary controls for marital status, sex, number of children, retirement status, education, income, race, ethnicity, fair/poor health status, ADLs, age, year, and state fixed effects and are estimated using population weights. Standard errors clustered at the state level. * Significantly different at the $10 \%$ level; ${ }^{* *}$ at the $5 \%$ level; ${ }^{* * *}$ at the $1 \%$ level. 
Appendix Probit Results 
Table A-1: Probit Estimates of Effects of LTCI on Expectations

\begin{tabular}{lccccc}
\hline \hline & $(1)$ & $(2)$ & $(3)$ & $(4)$ & $(5)$ \\
& Inf Care & Inf Care-Kid & Inf Care-Relative & Inf Care-Other & High Pr(Beq) \\
\hline main & & & & & \\
LTCI Coverage & $-0.108^{* * *}$ & $-0.082^{* * *}$ & $-0.108^{* * *}$ & $0.057^{*}$ & $0.242^{* * *}$ \\
& $(0.026)$ & $(0.028)$ & $(0.032)$ & $(0.031)$ & $(0.024)$ \\
& & & & & \\
Marginal Effect & $-0.039^{* * *}$ & $-0.028^{* * *}$ & $-0.023^{* * *}$ & $0.011^{*}$ & $0.051^{* * *}$ \\
Mean of DV & 0.603 & 0.432 & 0.165 & 0.119 & 0.830 \\
Pseudo R & 0.063 & 0.106 & 0.091 & 0.046 & 0.093 \\
Clusters & 48 & 49 & 47 & 48 & 49 \\
Observations & 46,612 & 46,625 & 46,589 & 46,601 & 46,625 \\
\hline \hline
\end{tabular}

Source: HRS Waves 3-10 (1996-2010)

Notes: Dependent variable is as indicated in column heading. Sample includes individuals age 50 and above with above median income who report filing taxes. All specifications include binary controls for marital status, sex, number of children, retirement status, education, income, race, ethnicity, fair/poor health status, ADLs, age, year, and state fixed effects and are estimated using population weights. Standard errors clustered at the state level. ${ }^{*}$ Significantly different at the $10 \%$ level; ${ }^{* *}$ at the $5 \%$ level; ${ }^{* * *}$ at the $1 \%$ level. 
Table A-2: Probit Estimates of Effects of LTCI on Informal Care Utilization

(1) (2) (3)

Wave $t$ to $t+1 \quad$ Wave $t$ to $t+2$ Wave $t$ to $t+3$

\begin{tabular}{lccc}
\hline main & & & \\
LTCI Coverage & $-0.107^{* * *}$ & $-0.085^{* * *}$ & $-0.088^{* * *}$ \\
& $(0.033)$ & $(0.028)$ & $(0.029)$ \\
& & & \\
Marginal Effect & $-0.012^{* * *}$ & $-0.014^{* * *}$ & $-0.018^{* * *}$ \\
Mean of DV & 0.091 & 0.154 & 0.210 \\
Pseudo R & 0.272 & 0.278 & 0.279 \\
Clusters & 46 & 48 & 49 \\
Observations & 46,592 & 39,420 & 31,891 \\
\hline \hline
\end{tabular}

Source: HRS Waves 3-10 (1996-2010)

Notes: Dependent variable is as indicated in column heading. Sample includes individuals age 50 and above with above median income who report filing taxes. All specifications include binary controls for marital status, sex, number of children, retirement status, education, income, race, ethnicity, fair/poor health status, ADLs, age, year, and state fixed effects and are estimated using population weights. Standard errors clustered at the state level. * Significantly different at the $10 \%$ level; ** at the $5 \%$ level; *** at the $1 \%$ level. 
Table A-3: Probit Estimates of Effects of LTCI on Children Behavior
(1) $(2)$
(3)
(4)
(5)
(6)

$(7)$

Child Co-Res Child 10 mi. Child FT Child PT R Helps Child Child Helps R Will Names Child

\begin{tabular}{lccccccc}
\hline main & & & & & & \\
LTCI Coverage & $-0.185^{* * *}$ & -0.042 & 0.031 & $-0.058^{* *}$ & 0.040 & $-0.161^{* * *}$ & $0.298^{* * *}$ \\
& $(0.045)$ & $(0.033)$ & $(0.048)$ & $(0.025)$ & $(0.032)$ & $(0.041)$ & $(0.029)$ \\
& & & & & & & \\
Marginal Effect & $-0.049^{* * *}$ & -0.015 & 0.004 & $-0.017^{* *}$ & 0.014 & $-0.009^{* * *}$ & $0.096^{* * *}$ \\
Mean of DV & 0.245 & 0.513 & 0.919 & 0.243 & 0.569 & 0.031 & 0.592 \\
Pseudo R & 0.116 & 0.078 & 0.188 & 0.038 & 0.099 & 0.094 & 0.146 \\
Clusters & 48 & 47 & 45 & 49 & 49 & 42 & 49 \\
Observations & 43,124 & 42,348 & 42,397 & 42,455 & 43,079 & 42,590 & 42,552 \\
\hline \hline
\end{tabular}

Source: HRS Waves 3-10 (1996-2010)

Notes: Dependent variable is as indicated in column heading. Sample includes individuals age 50 and above with above median income who report filing taxes. All specifications include binary controls for marital status, sex, number of children, retirement status, education, income, race, ethnicity, fair/poor health status, ADLs, age, year, and state fixed effects and are estimated using population weights. Standard errors clustered at the state level. * Significantly different at the $10 \%$ level; ** at the $5 \%$ level; *** at the $1 \%$ level. 